\title{
Study on the Calculation Methods and Parameters Effect on the Stability of Loess Slope
}

\begin{abstract}
Taken the natural loess slopes in the Linfen area as the engineering example, analyze the relationship between the slope size parameters (height of slope, angle of slope), material parameters(soil cohesion, friction angle) and the stability safety coefficient of slope with different calculation method. The results show that: Different limit equilibrium method has less influence on the height of slope, cohesion and friction angle than angle of slope. The safety coefficient of loess slope have a good correlation to the high, cohesion and friction angle of the slope. The height of slope is negatively related to the safety coefficient, but the cohesion and friction angle are positively related to safety coefficient. The influence of cohesion and friction angle is greater than the height on the safety coefficient of slope. Therefore, we should pay special attention to parameters of cohesion and friction angle values in the stability calculation of loess slope.
\end{abstract}

Sun Zhijie

Shanxi Transportation Research Institute 18835130490@163.com

Key Laboratory of Highway Construction \& Maintenance Technology in Loess Region, Ministry of Transport, Taiyuan,

Keywords: loess slope; stability; calculation method; parameter; limit equilibrium methods

\section{INTRODUCTION}

The stability of loess slope has always been an important problem in geotechnical engineering. The stability evaluation results of loess slope is directly related to the quality of slope ${ }^{[1]}$.In the stability calculation of loess slope, the choice of loess slope strength parameters and calculation method has influence on stability evaluation results of slope. Studies have shown that, in the stability calculation of loess slope, evaluates deviation due to different calculation methods is much smaller than the deviation caused by parameters selection ${ }^{[2]}$. Therefore, the of choice strength parameters has an important significance to stability evaluation of slope .Li Ping et $\mathrm{al}^{[3-5]}$. use cohesion and internal friction angle measured in the highway slopes of Shaanxi and Gansu provinces as the random variable reference value. Reliability simulated were done to the high loess slope of different regions, the effect on the failure probability which caused by height of slope, grade of slope and strength parameters of slope were systematic analyzed, the relationship between the failure probability and the stability coefficient were studied. Zhang Changliang et $\mathrm{al}^{[6]}$. analysis of influence of the the slope stability coefficient on the height, grade, cohesion and internal friction angle value of slope in Shaanxi Guanzhong-Huangling area by Mohr Coulomb strength theory. Zhang Shaohong ${ }^{[7]}$ analyzed on loess slope stability calculation parameters on the sensitivity of calculation results with the Sweden Arc Method. Other scholars have conducted relevant research ${ }^{[8-11]}$.

In order to further discuss the influence of calculation parameters of loess slope safety factor to the stability of slope, the loess slope in Linfen area of Shanxi province were taken as an example, using the different limit equilibrium methods, to study the slope parameters (height of slope, angle of slope, soil cohesion, friction angle) effects on the stability safety coefficient of slope.

\section{PROJECT OVERVIEW}

Taken the natural loess slopes in the Linfen area as the investigation object, focus on the survey and statistics of loess slope height around 20M (as shown in Fig.1), its lithology are loess $\mathrm{Q}_{3}$, slope can be approximated as linear, undisturbed loess of different parts in slope were taken to do indoor physical mechanics parameter test. 


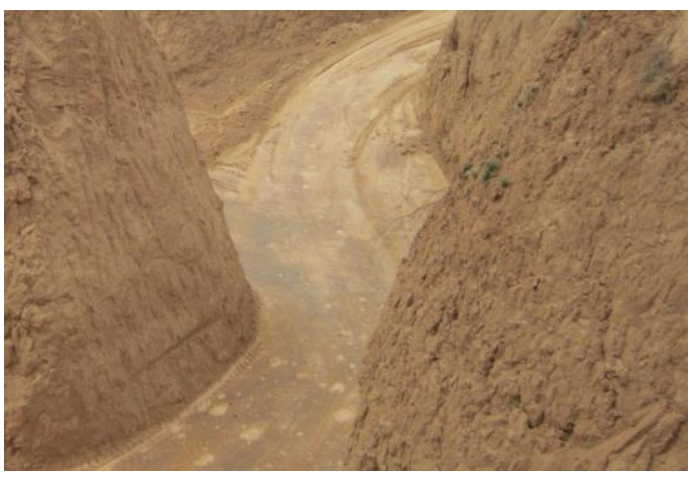

Figure 1. loess slope

III. COMPUTATIONAL MODEL

The size of basic slope model is shown in Fig.1. In the basic model, the height of slope is $20 \mathrm{~m}$, the angle of slope is $45^{\circ}$. The material parameters of basic slope are shown in table 1 . Bulk density is $25 \mathrm{kN} / \mathrm{m}^{3}$ cohesion is $42 \mathrm{kPa}$, internal friction angle is $17^{\circ}$. The limit equilibrium computational methods including Slice method, Bishop method, Janbu method, M-P method and Spencer method.

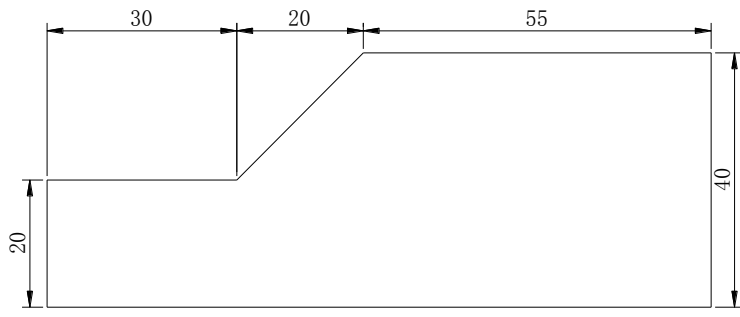

Figure 2. size of basic slope model

TABLE I . Basic model calculation parameters

\begin{tabular}{cccccc}
\hline type & density $/ \mathrm{kg} \cdot \mathrm{m}^{-3}$ & Elastic Modulus $/ \mathrm{MPa}$ & Poisson's ratio & cohesion $/ \mathrm{kPa}$ & friction angle $/{ }^{\circ}$ \\
\hline soil & 2.5 & 150 & 0.3 & 42 & 17 \\
\hline
\end{tabular}

IV. ANALYSIS OF FACTORS LOESS TUNNEL

To analyze the relationship between the slope size parameters (height of slope ,angle of slope), material parameters(soil cohesion, friction angle) and the stability safety coefficient of slope. The paper mainly analyzes the following height of slope, such as $10 \mathrm{~m}$, $20 \mathrm{~m}, 30 \mathrm{~m}, 40 \mathrm{~m}$ and $50 \mathrm{~m}$. The following angle of slope,such as $30^{\circ}, 35^{\circ}, 40^{\circ}, 45^{\circ}, 50^{\circ}, 55^{\circ}$ and $60^{\circ}$. The following cohesion, such as $10 \mathrm{kPa}, 20 \mathrm{kPa}, 30 \mathrm{kPa}$, $40 \mathrm{kPa}, 50 \mathrm{kPa}, 60 \mathrm{kPa}$ and $70 \mathrm{kPa}, 80 \mathrm{kPa}$ and $90 \mathrm{kPa}$. The following friction angle, such as $0^{\circ}, 5^{\circ}, 10^{\circ}, 15^{\circ}$, $20^{\circ}, 25^{\circ}, 30^{\circ}, 35^{\circ}$ and $40^{\circ}$.

Analysis results used by Geo/Slope are shown as follows.

\section{A. The impact of slope height}

The material parameters use basic model calculation parameters which are shown in table 1 . The height of slope is increased from $10 \mathrm{~m}$ to $50 \mathrm{~m}$. The curves of safety coefficient with height of slope are shown in figure 3.

In the Fig.3, with the increase of the height of slope, the safety coefficient of slope reduced. When the height of slope increased from $10 \mathrm{~m}$ to $20 \mathrm{~m}$, the safety coefficient decreased maximally, reduced about 0.65. With the increase of height of slope, safety coefficient decreased amplitude smaller. The slope height increased from $40 \mathrm{~m}$ to $50 \mathrm{~m}$, the safety coefficient only decreases about 0.055 .

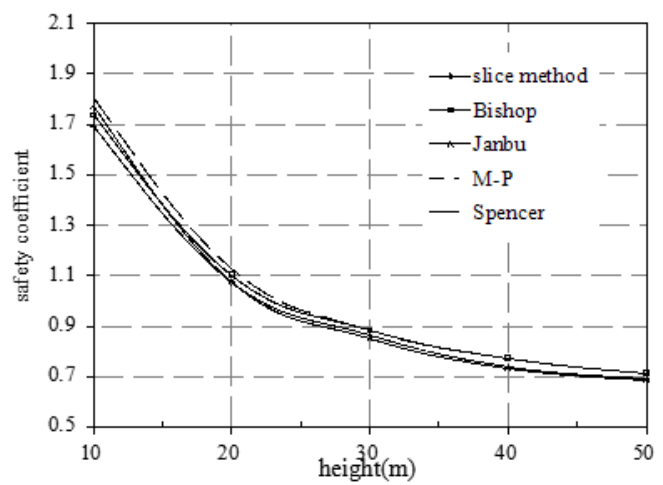

Figure 3. safety coefficient with height of slope

The slope height is greater than $20 \mathrm{~m}$, the safety coefficient of slope is less than 1.1 , if it continues to increase the height of slope, we need to take measures to improve the stability of the slope.

The calculate results of 5 kinds of limit equilibrium methods are similar. The maximum calculate difference is on the condition of $10 \mathrm{~m}$ slope height.

\section{B. The impact of slope angle}

The material parameters use basic model calculation parameters. The angle of slope is increased 
from $30^{\circ}$ to $60^{\circ}$. The curves of safety coefficient with angle of slope are shown in Fig.4.

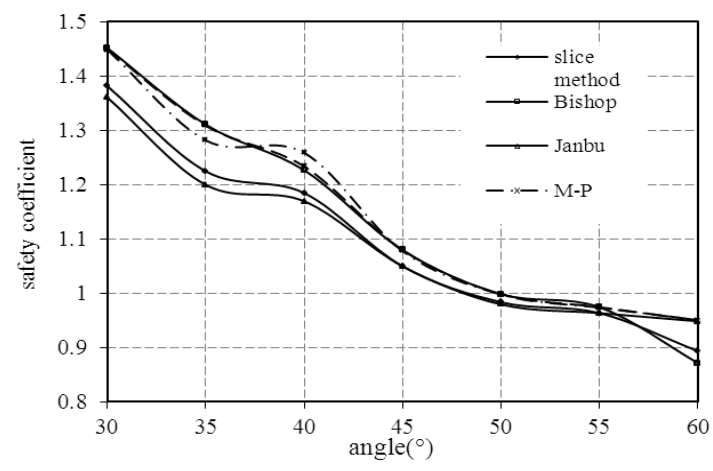

Figure 4. safety coefficient with angle of slope

In the Fig.4, on the whole, with the increase of the angle of slope, the safety coefficient of slope reduced. But when the angle of slope increased from $35^{\circ}$ to $40^{\circ}$ or from $50^{\circ}$ to $55^{\circ}$, the safety coefficient decrease slowly.

Slope angle greater than 45 degrees, the slope safety coefficient is less than 1.1, if increase the slope angle, we need to take measures to improve the stability of the slope.

Unlike the curve safety coefficient with the height of slope, from $30^{\circ}$ to $55^{\circ}$, Bishop and Spencer calculation results were similar, the calculation results of the other 3 methods are large difference, the maximum calculate difference is on the condition of $30^{\circ}$ slope angle. With the increase of slope angle, the difference of calculation results gradually decreased.

\section{The impact of cohesion}

The material parameters use basic model calculation parameters. The cohesion of slope is increased from $10 \mathrm{kPa}$ to $90 \mathrm{kPa}$. The curves of safety coefficient with cohesion of slope are shown in Fig.5.

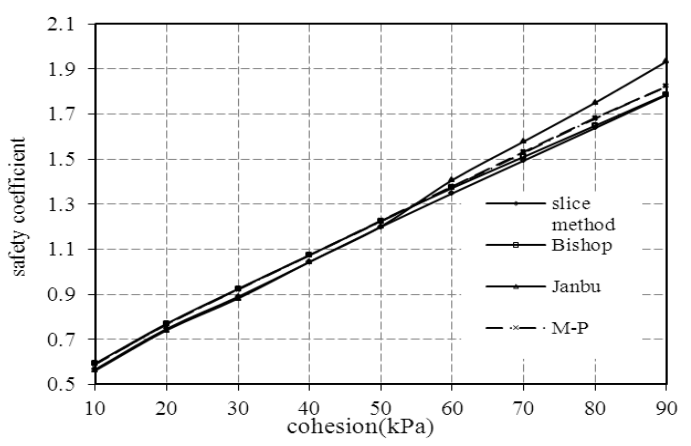

Figure 5. safety coefficient with cohesion of slope In the Fig.5, on the whole, the safety coefficient increases with the increase of the cohesion. There was a linear relationship between the safety coefficient and cohesion.

Cohesion is less than $40 \mathrm{kPa}$, the slope safety coefficient is less than 1.1.

In addition to Janbu, calculation results of other 3 methods are similar. While the cohesive force is larger than $50 \mathrm{kPa}$, the calculation results difference between Janbu and other 4 methods are more and more distantly with the increase of cohesion.

\section{The impact of friction angle}

The material parameters use basic model calculation parameters. The friction of slope is increased from $0^{\circ}$ to $40^{\circ}$. The curves of safety coefficient with friction angle of slope are shown in Fig.6.

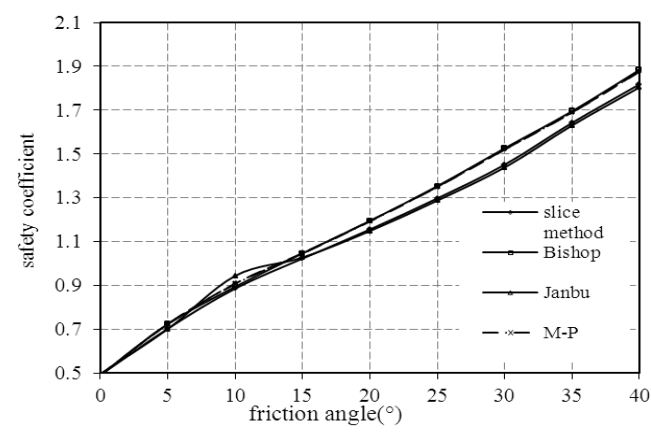

Figure 6. safety coefficient with friction angle of slope

In the Fig.6, on the whole, the safety coefficient increases with the increase of the friction angle. There was a linear relationship between the safety coefficient and friction angle.

The friction angle less than $20^{\circ}$, the slope safety coefficient is less than 1.1.

While the friction angle greater than $15^{\circ}$, the difference of calculation method increases with the increase of friction angle, and tend to be stable. The results are broadly divided into two groups, Janbu and slice method is one group, and the other 3 methods were similar.

\section{CONCLUSION}

Through study on the relationship between loess slope calculation parameters and safety factor, the research results show that:

(1) Different limit equilibrium method has less influence on the height of slope, cohesion and friction 
angle than angle of slope.

(2) The safety coefficient of loess slope have a good correlation to the high, cohesion and friction angle of the slope. The height of slope is negatively related to the safety coefficient, but the cohesion and friction angle are positively related to safety coefficient.

(3) The influence of cohesion and friction angle is greater than the height on the safety coefficient of slope. Therefore, we should pay special attention to parameters of cohesion and friction angle values in the stability calculation of loess slope.

(4) The finite element strength reduction method and the finite element limit equilibrium method can be used for slope analysis.

\section{REFERENCES}

[1] Xia Yuanyou, Li Mei. Evaluation Method Research of Slope Stability and Its Developing Trend[J]. Chinese Journal of Rock Mechanics and Engineering, 2002, Vol.21(7), pp: 1087-1091
[2] Liu Zudian. Loess Mechanics and Engineering [M]. Shaanxi Science and Technology Press, 1997.

[3] Li Ping, Wang Binggang, Li TongLu, et al. Study of Reliability for Loess Cutting High Slopes in Shaanxi Province[J]. China Journal of Highway and Transport, 2009, Vol.22(6), pp: 18-25.

[4] Li Ping, Wang Binggang, Li Tonglu. Study of

analogism used in highway cutting loess slope design[J].Journal of Highway and Transportation Research and Development, 2009, Vol.26(1), pp: 1-5.

[5] Li Ping, Huang Lijuan, Li Zhenjiang, et al. Study of reliability for loess high slopes in Gansu area[J]. Rock and Soil Mechanics, 2013, Vol.34(3), pp: 811-817

[6] Zhang Changliang, Liping, Tao Fupin, et al. Research of Effect of Strength Index on Loess Slope Stability[J]. Rock and Soil Mechanics, 2011, Vol.28(3) : pp: 20-24.

[7] Zhang Shaohong. Analysis on Sensitivity of Parameter in Stability Calculation of Loess Slope[J]. Journal of Water Resources and Architectural Engineering, 2003, Vol.1(3), pp: 40-42.

[8] Gong Xianwei, Yi Nianping, Zhang Xingui. Discussion for the Safety Facto $r$ of Slope Project[J]. Journal of Guangxi University :Nat Sci Ed, 2006 , Vol.31(3), pp:265-270.

[9] Tan Xiaohui, Wang Jianguo, Liu Xinrong, et al. Finite Element Reliability Computation and Sensitivity Analysis of Slope Stability[J] .Chinese Journal of Rock Mechanics and Engineering, 2007, Vol.26(1), pp:115-122

[10] Jia Houhua, He Huaijian. Analysis of Fuzzy-random Reliability of Slope Stability[J]. Rock and Soil Mechanics, 2003, Vol.24(4), pp: 657-660.

[11] Chen Qiang, Li Yaozhuang .Reliability Analysis

and Evaluation for Slope Stability[J] .Subgrade Engineering, 2007, Vol. (1), pp:1-2. 